\title{
Glucagon Secretory Responses to Insulin-induced Hypoglycemia and Arginine in Streptozotocin-induced Diabetic Dogs
}

\author{
Mitsukazu GOTOH*, Jun OKAMURA*, Morito MONDEN* \\ AND KENJI SHIMA** \\ *Second Department of Surgery and **Department of Medicine and \\ Geriatrics, Osaka University Medical School, Osaka 553
}

\begin{abstract}
To clarify whether the reactivity of $A$ cells is regulated by $B$ cell function in the pancreas, plasma glucagon (IRG) responses to insulin-induced hypoglycemia and to arginine infusion were evaluated in streptozotocin (STZ; total $40 \mathrm{mg} / \mathrm{kg}$ ) treated and control dogs. There was no significant rise in plasma IRG levels during the insulininduced hypoglycemia in the STZ-treated dogs. In contrast, arginine enhanced the IRG secretion from the pancreas to a similar extent in the two groups. This was deduced from the difference between IRG levels in the pancreaticoduodenal and peripheral veins. Neither intravenous glucose nor arginine infusion resulted in a significant rise in plasma insulin (IRI) levels in the STZ-treated dogs. IRI content in the pancreases of STZ-treated dogs was significantly reduced to 5 percent below the levels in the control dogs. The IRG content for control and STZ-treated dogs did not differ. These results indicate that while the responsiveness of A cells to hypoglycemia may depend on the secretory capacity of B cells, such is not the case with arginine.
\end{abstract}

The lack of glucagon response to hypoglycemia and the preserved or elevated response to arginine has been well documented, not only in cases of juvenile diabetes (Gerich et al., 1973), but also in cases of insulin dependent diabetes where the secretory capacity of pancreatic B cells was totally exhausted (Shima et al., 1977; Reynolds et al., 1977). In a previous study, we reported that A cell responsiveness to hypoglycemia correlated well with the insulin secretory ability of the B cells, but that such was not the case with A cell responsiveness to arginine (Shima et al., 1979). Various experiments have been done in attempt to explain this discrepancy and "in vitro" systems in

Received October 19, 1982 drug-induced diabetic animals were often used (Weir et al., 1976; Hermansen et al., 1979). As there is no convincing evidence concerning the "in vivo" glucagon secretion of diabetic animals, we investigated the " $i n$ vivo" glucagon secretion to hypoglycemia and to arginine in streptozotocin-treated dogs. We would like to emphasize here, that we have attempted to throw light on the matter by measuring the insulin and glucagon content in the pancreas of the animals investigated.

\section{Materials and Methods}

Diabetes was induced in 7 healthy adult mongrel dogs of both sexes weighing $8-10 \mathrm{~kg}$ by giving them streptozotocin (STZ: Upjohn, C-47552, Lot No. 3029 
J). The dose of STZ was $20 \mathrm{mg} / \mathrm{kg} /$ day for two days. STZ was dissolved in a citrate buffer at $\mathrm{pH}$ 4.5 and injected intravenously within $5 \mathrm{~min}$. These diabetic dogs were treated with $12 \mathrm{U}$ of highly purified porcine insulin (Monotard, Novo Industries, Denmark) daily for 6 days. Insulin was not given on the morning of the experiment.

Plasma glucagon (IRG) response during an insulin tolerance test (ITT) and insulin (IRI) response during an intravenous glucose tolerance test (IVGTT) were evaluated in these dogs before and after the STZadministration. The ITT was performed on the 7th and the IVGTT on the 8th day after the administration of STZ. Plasma IRI and IRG responses during the arginine infusion test (AIT) were also examined in the same dogs about three hours after the IVGTT, when the elevated blood glucose levels during IVGTT returned to the value at the beginning of IVGTT. This self controlled study would minimize the variation in glucagon secretion in different dogs.

Another group of 8 healthy dogs weighing 8-12 $\mathrm{kg}$ were subjected to an AIT as the control. All the dogs were killed after the AIT and the IRI and IRG in the pancreas were determined.

All tests were performed with the dogs under pentobarbital anaesthesia $(25 \mathrm{mg} / \mathrm{kg}$ i. v.). The ITT was carried out by administering $0.5 \mathrm{U} / \mathrm{kg}$ of insulin (Actrapid MC, Novo Industries, Denmark) to the control and $2.0 \mathrm{U} / \mathrm{kg}$ to the STZ-treated dogs. Blood samples were collected from the femoral vein at timed intervals for $180 \mathrm{~min}$ before and after the insulin injection. The IVGTT was carried out by giving $0.3 \mathrm{~g} / \mathrm{kg}$ of 50 percent glucose rapidly and blood samples were taken at timed intervals for 30 min, in a manner similar to that described above. The AIT was performed by infusing $70 \mathrm{ml}$ of 10 percent L-arginine solution into the antecubital vein for $30 \mathrm{~min}$ and then collecting blood from the catheters inserted into the pancreaticoduodenal and femoral veins.

The blood samples were immediately transferred into ice-cold tubes containing $1.2 \mathrm{mg}$ of EDTA and $500 \mathrm{U}$ of lyophilized aprotinine (Trasylol) per $\mathrm{ml}$ of blood. The samples were centrifuged as soon as possible and the plasma was stored at $-20^{\circ} \mathrm{C}$ until assay. The IRG was measured by means of radioimmunoassay using AGS 18 which is specific for pancreatic glucagon (Shima et al., 1977). The IRI was measured by a solid phase technique using a Phadebas kit (Pharmacia, Uppsala, Sweden). Porcine glucagon and insulin were used as the standard materials for the respective assays. Glucose was measured by the o-toluidine method.

The pancreases removed at autopsy were immediately frozen and stored at $-70^{\circ} \mathrm{C}$ until the extraction procedures. Each whole pancreas was cut into small pieces with scissors, minced well to diminish the topographical difference in the hormonal concent- ration. About $5 \mathrm{~g}$ of this minced tissue was homogenized with acid alcohol solution, using a polytron according to the method of Kenny (1955). Samples of the homogenate were used for measuring IRI and IRG content.

All the data are expressed as mean \pm SEM. The statistical analysis was done by using Student's $t$-test.

\section{Results}

In the control dogs, the plasma IRI levels rose significantly in response to intravenous glucose administration (Fig. 1). No IRI secretion responding to a further rise in blood glucose levels was noted in the STZtreated dogs.

In ITT, $2.0 \mathrm{U} / \mathrm{kg}$ of exogenous insulin decreased the amount of blood glucose from $200 \pm 14 \mathrm{mg} / \mathrm{dl}$ to $43 \pm 14 \mathrm{mg} / \mathrm{dl} 105 \mathrm{~min}$ after injection into the STZ-treated dogs (Fig. 2). The blood glucose levels in the control dogs fell from $99 \pm 4 \mathrm{mg} / \mathrm{dl}$ to $30 \pm 2 \mathrm{mg} / \mathrm{dl} 90 \mathrm{~min}$ after the injection of $0.5 \mathrm{U} / \mathrm{kg}$ of insulin. The blood glucose levels dropped most rapidly during the first $15 \mathrm{~min}$ in both groups and the drop during this period in the STZtreated dogs was $56 \pm 13 \mathrm{mg} / \mathrm{d} 1 / 15 \mathrm{~min}$, which was comparable to the $53 \pm 4 \mathrm{mg} / \mathrm{dl} / 15 \mathrm{~min}$ in the control ones. Furthermore, there was no significant difference in the nadirs of blood glucose levels between the STZ-treated and control groups. The insulin-induced hypoglycemia produced a significant IRG release in the control dogs and levels rose from the basal value of $228 \pm 45 \mathrm{pg} / \mathrm{ml}$ to $357 \pm 77 \mathrm{pg} / \mathrm{ml} 60 \mathrm{~min}$ after the insulin injection. In the STZ-treated dogs, however, no significant rise in the IRG levels from the basal value of $232 \pm 33 \mathrm{pg} / \mathrm{ml}$ was observed during the hypoglycemia. The difference between the plasma IRG levels of the STZ-treated and the control dogs in ITT was significant at 30, 45, 60 and $90 \mathrm{~min}$.

In AIT, the plasma IRI levels rose significantly in the control dog (Fig. 3). No IRI secretion responding to arginine was noted in the STZ-treated dogs. The secretory 


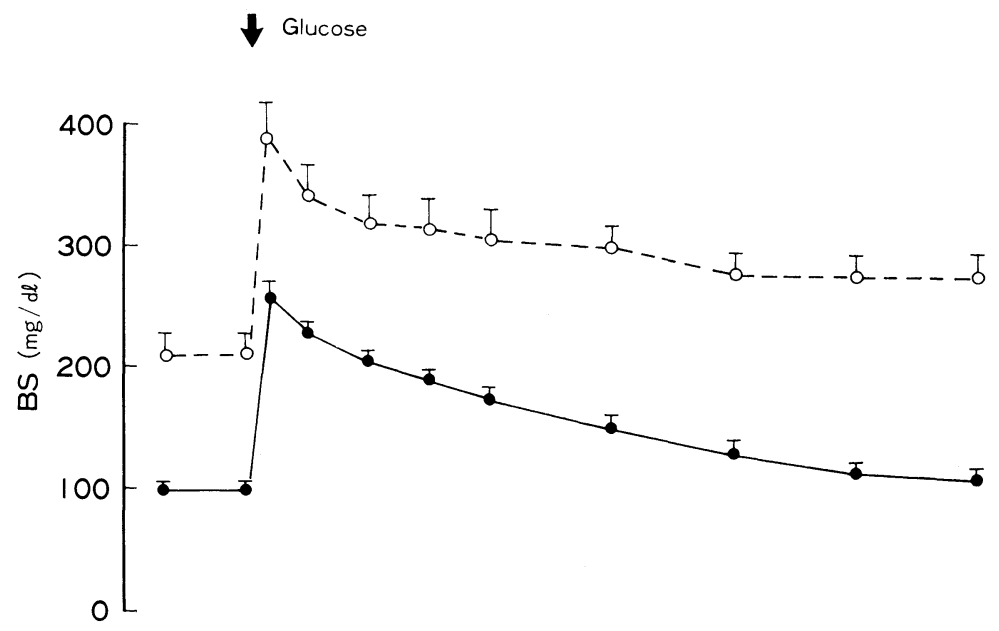

Fig. 1. Blood glucose and IRI levels during IVGTT in control (-) and STZtreated $(\bigcirc \cdots \bigcirc)$ dogs $(\mathrm{N}=7)$. $x \times \mathrm{p}<0.01$ vs the basal value.

$\star \mathrm{p}<0.05$, $\star \star \mathrm{p}<0.01$ vs STZ-treated.

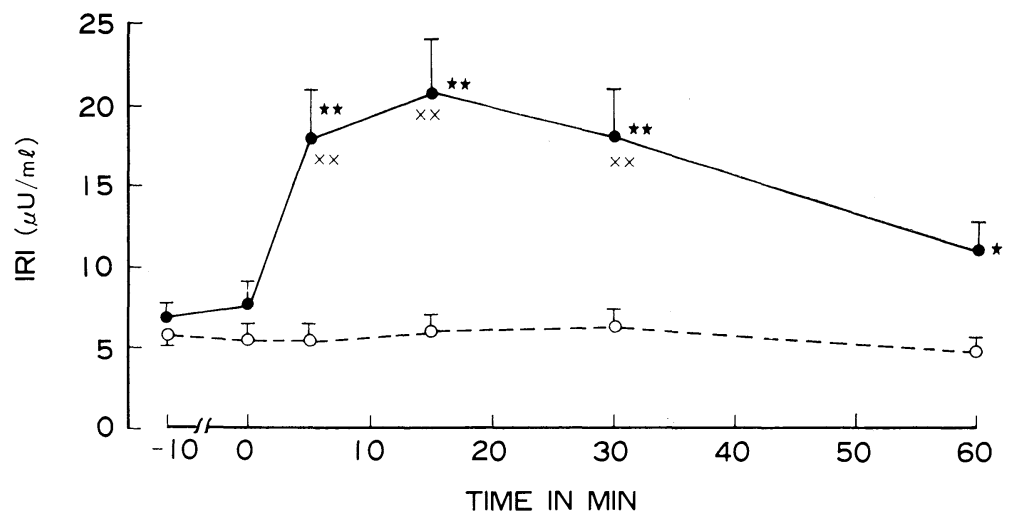

capacity of B cells in response to the stimuli was found to be totally exhausted after STZ administration.

In contrast, infusion of arginine resulted in an IRG release in the STZ-treated dogs as well as in the control dogs, as shown in Fig. 3. IRG levels in the pancreaticoduodenal and femoral veins during AIT were significantly higher than the corresponding basal value, in both groups. IRG levels in the STZ-treated dogs were significantly greater at $10 \mathrm{~min}$ in the femoral vein, and at $60 \mathrm{~min}$ in the pancreaticoduodenal and the femoral vein, as compared to the corresponding values in the control dogs. The
IRG secretion from the pancreas attached to the duodenum into the pancreaticoduodenal vein, calculated by subtracting the IRG levels in the femoral vein from those in the pancreaticoduodenal vein, was not significantly different in the STZ-treated from that in the control dogs.

IRI content in the pancreases of the STZ-treated dogs was $0.4 \pm 0.1 \mathrm{U}$ per pancreas, significantly smaller than that noted in the control dogs, which was $10.7 \pm 1.7 \mathrm{U}$ per pancreas ( $\mathrm{p}<0.001$, Table 1$)$. The amount of IRG in the pancreases of the STZ-treated dogs was $26.5 \pm 5.6 \mu \mathrm{g}$ per pancreas, while the level was $35.5 \pm 5.0 \mu \mathrm{g}$ per pancreas in 

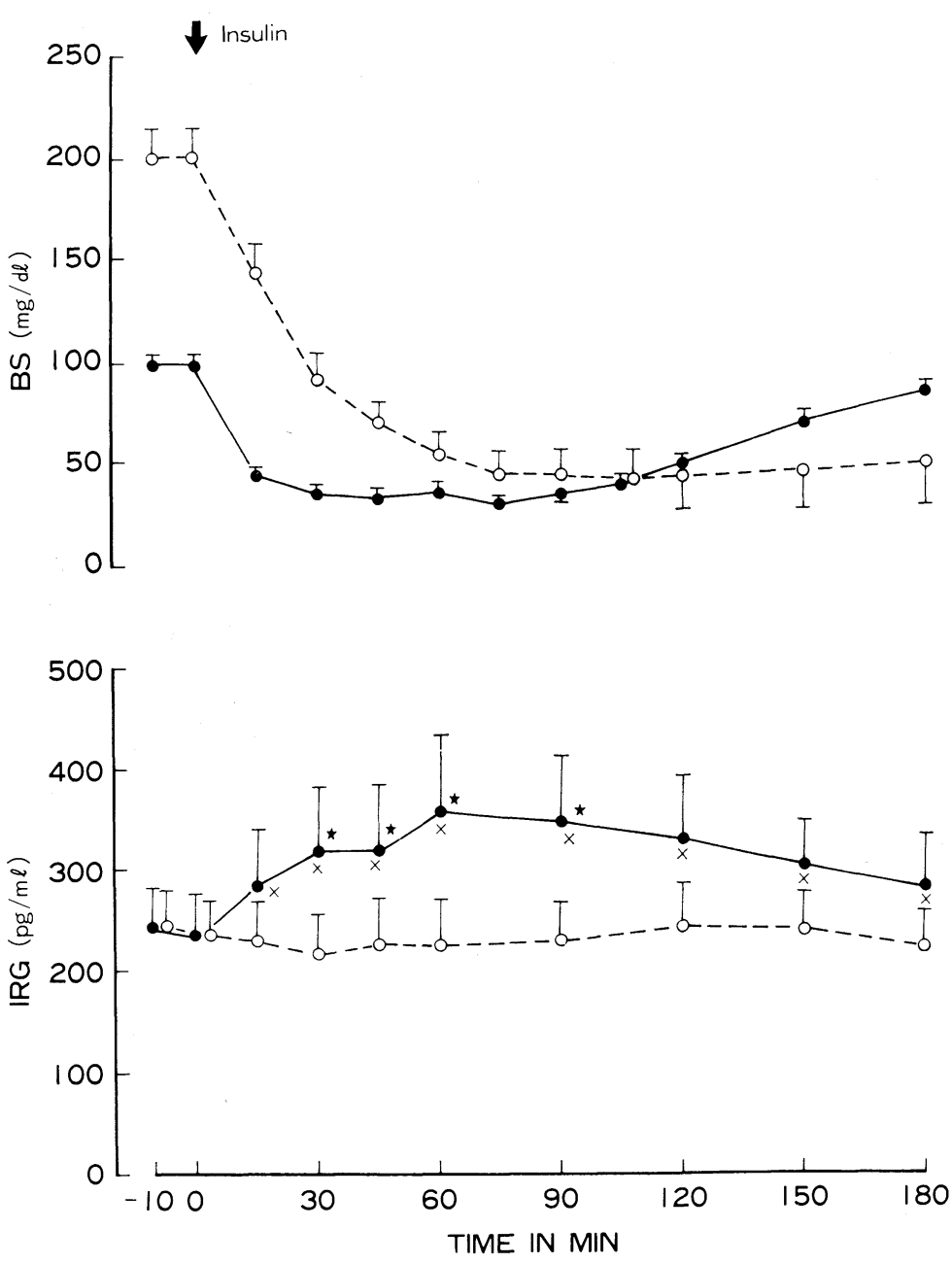

Fig. 2. Blood glucose and IRG levels during the insulin tolerance test in control (O) and STZ-treated $(\bigcirc \cdots \bigcirc)$ dogs $(\mathrm{N}=7)$. $\times \mathrm{p}<0.05$ vs the basal value. $\star \mathrm{p}<0.05$ vs STZ-treated. the control dogs. There was no significant difference between the IRG levels in the STZ-treated and the control dogs.

\section{Discussion}

The diabetic dogs whose insulin secretory capacity was totally reduced by STZ-treatment revealed an apparent discrepancy: the IRG secretion in response to arginine was well maintained, while the insulin-induced hypoglycemia did not cause any significant increase in the secretion of IRG.
As we reported previously (Matsuyama et al., 1978), extrapancreatic glucagon of the pancreatic type does not respond to hypoglycemia, but to arginine (Blazquez et al., 1976). To exclude the possibility of IRG secretion from A cells other than those of pancreatic origin responding to arginine, we measured the IRG "secretion" into the pancreaticoduodenal vein to determine the difference between the IRG levels between in the pancreaticoduodenal and peripheral veins. We found that the arginine-stimulated IRG "secretion" from A cells in the STZ-treated dogs did not differ from the 

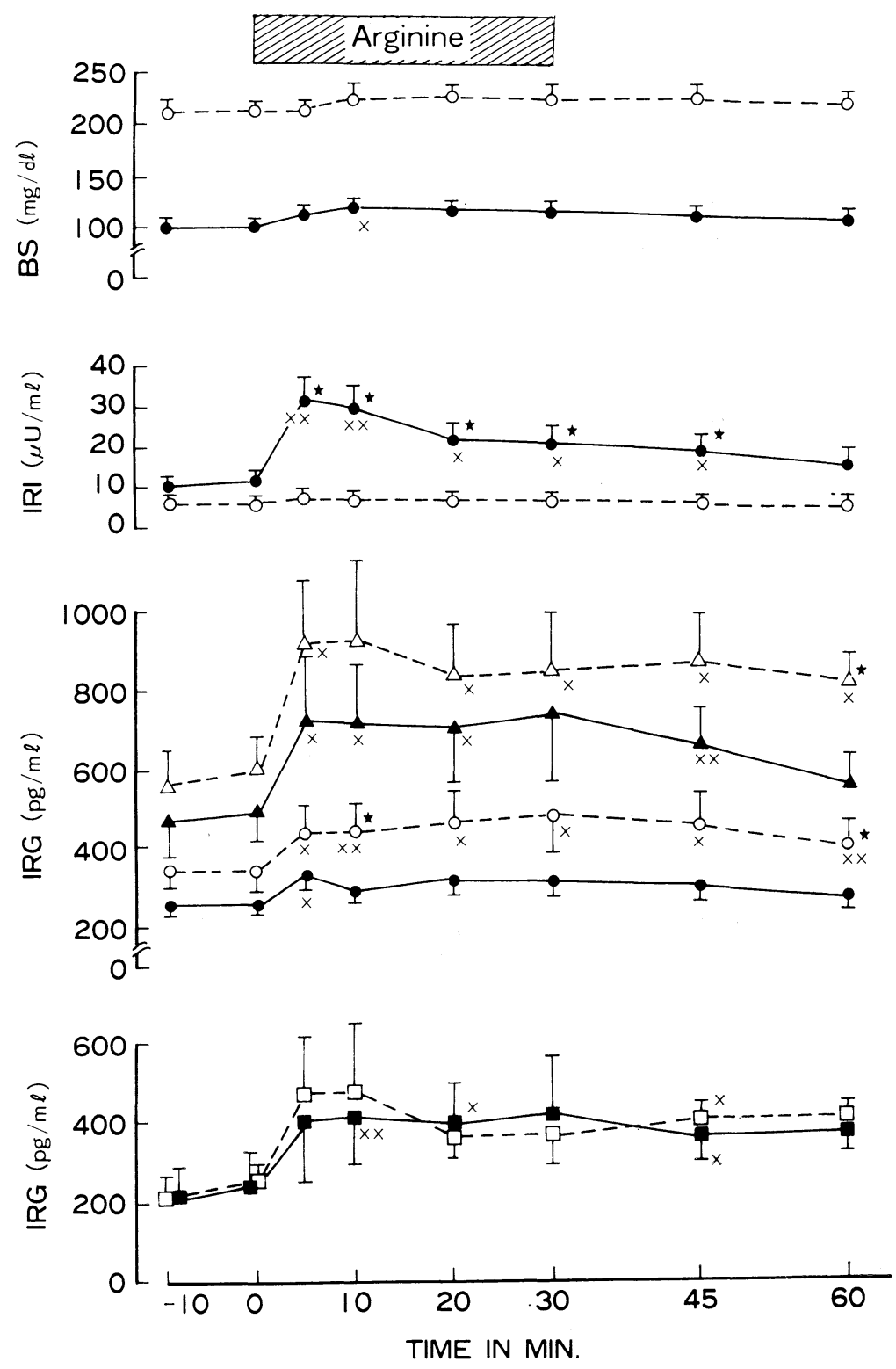

Fig. 3. Blood glucose, IRI and IRG levels during arginine infusion test in control $(\mathrm{N}$ $=8)$ and STZ-treated $(\mathrm{N}=$ 5) dogs. (O-O): femoral vein in control, $(\bigcirc \cdots \bigcirc)$ : femoral vein in STZ-treated, $(\boldsymbol{\Delta}-\mathbf{\Delta})$ : pancreaticoduodenal vein in control, $(\triangle-\triangle)$ : pancreaticoduonal vein in STZ-treated, $(\mathbf{D}-\mathbf{})$ : difference between levels in the pancreaticoduodenal and femoral veins in control, $(\square \cdots \square)$ : difference between in the pancreaticoduodenal and femoral vein in STZtreated.

$\times \mathrm{p}<0.05, \quad x \times \mathrm{p}<0.01$ vs the basal value. $\star \mathrm{p}<0.05$ vs control or STZ-treated.

secretion in the control dogs.

The secretion of IRG stimulated by insulin-induced hypoglycemia is considered to be influenced by several factors including the degree of hypoglycemia and the rate of decrease in blood glucose (Gerich et al., 1974). We found that the rate of the fall and the nadirs of blood glucose levels in the
STZ-treated dogs did not differ from the findings in the control dogs. The hypoglycemia induced in this study was thought to be sufficient to evoke the secretion of IRG in the STZ-treated dogs as well as in the control dogs. However, no significant response to insulin-induced hypoglucemia was observed in the STZ-treated dogs. 
Table 1. IRI and IRG concentration in canine pancreases

\begin{tabular}{lcc}
\hline \hline & Control & STZ-treated \\
\hline $\begin{array}{l}\text { Weight of Pancreas (g) } \\
\text { IRI Concentration }\end{array}$ & $19.3 \pm 1.4$ & $16.2 \pm 0.9$ \\
$\quad 543 \pm 61$ & $23 \pm 7 \dagger$ \\
Total IRI Content (U) & $10.7 \pm 1.7$ & $0.4 \pm 0.1 \dagger$ \\
IRG Concentration & $1,936 \pm 319$ & $1,564 \pm 272$ \\
$\quad$ (ng/g tissue) & & \\
Total IRG Content $(\mu \mathrm{g})$ & $35.5 \pm 5.0$ & $26.2 \pm 5.6$ \\
\hline & $\dagger: \mathrm{p}<0.001$ vs control
\end{tabular}

It is well known that anaesthesia may affect pancreatic hormonal secretion and glucose metabolism (Davidson, 1971 ; Bailey and Flatt, 1980). We evaluated the hormonal secretions in the STZ-treated dogs under the same conditions as the control dogs which showed significant insulin and glucagon secretion in response to stimuli. Therefore, the disappearance of the IRG response to hypoglycemia in the STZ-treated dogs could not be considered to result from the anaesthesia itself.

Absolute or relative hyperglucagonemia during a glucose load and an exaggerated glucagon response to arginine were observed in experimental animals (Blazquez et al., 1977 ; Braaten et al., 1977) and in diabetic patients (Aydin et al., 1977; Raskin et al., 1976). This abnormal A cell reaction can be corrected by exogenously administered insulin in either supraphysiologic or physiologic doses (Shichiri et al., 1979; Kawamori et al., 1980) and is thought to be secondary to insulin deficiency or abnormal metabolic status. Therefore, it could be assumed that the absence of plasma IRG response to hypoglycemia in our diabetic dogs was due to incompleteness of their diabetic control. However, the A cells of type II diabetics whose fasting blood glucose levels are comparable with those of our diabetic dogs respond discernibly to insulin-induced hypoglycemia, though to a smaller extent than in normal subjects (Shima et al., 1977 ; Reynolds et al., 1977). Furthermore, normalization of the impaired reactivy of A cells after the insulin treatment occurs in response to an oral glucose as well as to an i.v. arginine load, but not necessarily so to insulin-induced hypoglycemia in diabetics (Ohneda et al., 1978). Together with these facts, no elevation of plasma IRG levels observed in our diabetic dogs during the hypoglycemic phase can be regarded as resulting from derangement of the diabetic control.

Glucagon response to hypoglycemia is markedly enhanced in healthy humans or animals when hypoglycemia is associated with hypoinsulinemia, as observed during phlorizin (Unger et al., 1962) or is ethanolinduced (Palmer and Ensinck, 1975) rather than insulin-induced hypoglycemia. In fact, the infusion of insulin in phlorizin-hypoglycemic dog decreases the hyperglucagonemia, even though it worsens the hypoglycemia (Dobbs, 1981). Thus, glucagon secretion in response to insulin-induced hypoglycemia may be affected by the exogenous insulin given to induce hypoglycemia. However, there was no significant difference between plasma IRI level at the nadir of blood glucose during insulin-induced hypoglycemia in the STZ-treated and the control dogs $(210 \pm 90,114 \pm 58 \mu \mathrm{U} / \mathrm{ml})$. It can be reasonably assumed that the difference between the plasma IRG response to hypoglycemia in the two groups was not accounted for by exogenous insulin.

Thus, selective insensitivity of A cells to hypoglycemia, which is consistent with that in human diabetes, was demonstrated in the STZ-treated dogs. In addition, there was a depletion of IRI and a preservation of IRG content in the STZ-treated pancreas, indicating that the B cells were selectively exhausted. This observation was in agreement with the volumetric quantitation of the pancreatic islets in STZ-treated rats (Hoftiezer and Carpentar, 1973). Such is probably the case in diabetic patients in whom the A cell reactivity to hypoglycemia has been studied. Normal islets consist of B cells, A 
cells and the other cells, which are all tightly connected (Orci et al., 1975) and are supposed to influence each other functionally by paracrine secretion (Orci and Unger, 1975) or through some mediators between the coupled cells such as $\mathrm{Ca}^{++}$or cyclic AMP (Leclercq-Meyer et al., 1975 ; Kalkhoff and Siegesmund, 1981; Toyota et al., 1975). As evidenced by the marked decrease in insulin content following STZ-administration, the cell to cell communication between $\mathrm{A}$ and $B$ cells in the islets, observed in normal pancreas, was destroyed and the interaction between these cells, if any, would not operate. A cells of the gastric fundus (Matsuyama et al., 1978), islets of juvenile diabetes (Gerich et al., 1973), and our STZtreated dogs, all of which lack contact with B cells, were not stimulated by hypoglycemic stimulus. These data taken together suggest that A cells require an enviroment of normal B cells to respond to insulininduced hypoglycemia.

\section{Acknowledgements}

We Wish to thank Mr. N. Sawazaki and Mr. A. Okamoto for their very capably technical assistance.

\section{References}

Aydin, I., P. Paskin and R. H. Unger (1977). The effect of short-term intravenous insulin administration on the glucagon response to a carbohydrated meal in adult onset and juvenile diabetes. Diabetologia 13, 629-636.

Bailey, C. J. and P.R. Flatt (1980). Insulin and glucagon during pentobarbitone anaesthesia. Diabete \& Metabolisme 6, 91-95.

Blazquez, E., L. Muñoz-Barragan, G. S. Patton, L. Orci, R. E. Dobbs and R. H. Unger (1976). Gastric A-cell function in insulin-deprived depancreatized dogs. Endocrinology 99, 1182-1188.

Braaten, J.T., G. R. Faloona and R.H. Unger (1974). The effect of insulin on the alpha-cell response to hyperglycemia in long-standing alloxan diabetes. J. Clin. Invest. 53, 1017-1021.

Davidson, M. B. (1971). Studies on the mechanism of pentobarbital-induced glucose intolerance. Horm. Metab. Res. 3, 243-247.

Dobbs, R. E. (1981). Control of glucagon secretion; Nutrients, gastroenteropancreatic hormones, calcium, and prostaglandins. In: Glucagon, physiology, pathophysiology, and morphology of the pancreatic A-cells (R. H. Unger and L. Orci ed.), Elsevier, New York. pp. 115-133.

Gerich, J.E., M. Langlois, C. Noacco, J. H. Karam and P. H. Forsham (1973). Lack of glucagon response to hypoglycemia in diabetes: Evidence for an intrinsic pancreatic alpha cell defect. Science 182, 171-173.

Gerich, J.E., V. Schneider, S. E. Dippe, M. Langlois, C. Noacco, J. H. Karam and P. H. Forsham (1974). Characterization of the glucagon response to hypoglycemia in man. J. Clin. Endocrinol. Metab. 38, 77-82.

Hermansen, K. H., Ørskov and S. E. Christensen (1979). Streptozotocin diabetes: A glucoreceptor dysfunction affecting D cells as well as B and A cells. Diabetologia 17, 385-389.

Hoftiezer, V. and A.-M. Carpenter (1973). Comparison of streptozotocin and alloxan-induced diabetes in the rat, including volumetric quantitation of the pancreatic islets. Diabetologia 9, 178184.

Kalkhoff, R. K. and K. A. Siegesmund (1981). Fluctuations of calcium, phosphorus, sodium, pottassium, and chlorine in single alpha and beta cells during glucose perifusion of rat islets. J. Clin. Invest. 68, 517-524.

Kawamori, R., M. Shichiri, M. Kikuchi, Y. Yamasaki and H. Abe (1980). Perfect normalization of excessive glucagon responses to intravenous arginine in human diabetes mellitus with the artificial beta-cell. Diabetes 29, 762-765.

Kenny, A. J. (1955). Extractable glucagon of the human pancreas. J. Clin. Endocrinol. Metab. 15, 1089-1105.

Leclercq-Meyer, V., O. Rebolledo, J. Marchand and W. J. Malaisse (1975). Glucagon Release: Paradoxical stimulation by glucose during calcium deprivation. Science 189, 897-899.

Matsuyama, T., R. Tanaka, K. Shima, K. Nonaka and S. Tarui (1978). Lack of gastrointestinal glucagon response to hypoglycemia in depancreatized dogs. Diabetologia 15, 471-474.

Ohneda, A., K. Watanabe, K. Horigome, T. Sakai, Y. Kai and S. Oikawa (1978). Abnormal response of pancreatic glucagon to glycemic changes in diabetes mellitus. J. Clin. Endocrinol. Metab. 46, 504-510.

Orci, L. and R. H. Unger (1975). Hypothesis: Functional subdivision of islets of Langerhans and possible role of D cells. Lancet 2, 1243-1244.

Orci, L., F. Malaisse-Lagae, M. Ravazzola, D. Rouiller, A. E. Renold, A. Perrelet and R. H. Unger (1975). A morphological basis for intercellular 
communication between $\alpha$ - and $\beta$-cells in the endocrine pancreas. J. Clin. Invest. 56, 1066-1070.

Palmer, J. P. and J. W. Ensinck (1975). Stimulation of glucagon secretion by ethanol-induced hypoglycemia in man. Diabetes 24, 295-300.

Raskin, P., I. Aydin and R. H. Unger (1976). Effect of insulin on the exaggerated glucagon response to arginine stimulation in diabetes mellitus. Diabetes 25, 227-229.

Reynolds, C., G. D. Molar, D. L. Horwits, A. H. Rubenstein, W. F. Taylor and N. S. Jiang (1977). Abnormalities of endogenous glucagon and insulin in unstable diabetes. Diabetes 26, 36-45.

Shichiri, M., R. Kawamori and H. Abe (1979). Normalization of paradoxic secretion of glucagon in diabetics who were controlled by the artificial beta cell. Diabetes 28, 272-275.

Shima, K., R. Tanaka, S. Morishita, S. Tarui, Y. Kumahara and M. Nishikawa (1977). Studies on the etiology of "brittle diabetes". Relationship between diabetic instability and insulinogenic reserve. Diabetes 26, 717-725.

Shima, K., R. Tanaka, N. Sawasaki and Y. Kumahara (1979). Relationship between secretory capacity of pancreatic A cell and of B cell. Horm. Metab. Res. 11, 451-452.

Toyota, T., S. Sato, M. Kudo, K. Abe and Y. Goto (1975). Secretory regulation of endocrine pancreas : Cyclic AMP and glucagon secretion. J. Clin. Endocrinol. Metab. 41, 81-89.

Unger, R. H., A. M. Eisentraut, M. S. McCall, L. L. Madison, K. R. Sims and L. Parman (1962). Measurements of endogenous glucagon in plasma and the influence of blood glucose concentration upon its secretion. J. Clin. Invest. 41, 682-689.

Weir, G. C., S. D. Knowlton, R. F. Atkins, K. X. Mckennan and D. B. Martin (1976). Glucagon secretion from the perfused pancreas of streptozotocin-treated rats. Diabetes 25, 275-282. 